\title{
Os indígenas nos Censos Demográficos brasileiros pré-1991
}

\author{
Claudio Santiago Dias Júnior ${ }^{\star}$ \\ Ana Paula Verona**
}

\section{Introdução}

A contagem da população indígena no Brasil sempre foi um desafio para os pesquisadores da área. De maneira geral, observa-se uma carência de dados demográficos sobre esses povos no país (PEREIRA; SANTOS; AZEVEDO, 2005). Apesar disso, pode-se notar um esforço muito grande por parte dos antropólogos, historiadores, médicos, enfermeiros, organizações não governamentais, órgãos estatais, universidades, dentre outros, na produção de dados que possibilitem a realização de estimativas passadas e presentes do tamanho da população indígena no Brasil (PAGLIARO; AZEVEDO; SANTOS, 2005). Como resultado, há uma falta de consenso no que se refere ao contingente populacional indígena no Brasil, em relação tanto aos números atuais quanto aos números do passado (PAGLIARO; AZEVEDO; SANTOS, 2005).

O Instituto Brasileiro de Geografia e Estatística (IBGE), órgão responsável pelas estatísticas oficiais do Brasil, também enfrenta o desafio de contabilizar os indígenas e, sem dúvida, vem fazendo um esforço muito grande para aprimorar a captação dessas informações. A reintrodução da categoria “indígena” no quesito cor/raça (Censo 1991), a mudança do quesito cor/raça para o questionário do universo, a reintrodução do quesito sobre língua falada e a inclusão do quesito etnia (Censo 2010) demonstram o compromisso do IBGE na elaboração de dados sobre os indígenas residentes no Brasil (CAMPOS; ESTANISLAU, 2016; IBGE, 1950, 2005, 2008, 2012).

Os esforços realizados pelo IBGE na captação das informações da população indígena vêm produzindo um crescimento significativo das análises deste subgrupo populacional

\footnotetext{
* Universidade Federal de Minas Gerais (UFMG), Belo Horizonte-MG, Brasil (claudio.austin@gmail.com; https://orcid. org/0000-0001-6038-6716).

** Universidade Federal de Minas Gerais (UFMG), Belo Horizonte-MG, Brasil (anapaulaverona@gmail.com; https://orcid. org/0000-0002-2062-9194).
} 
a partir dos dados censitários. Tal aumento pode ser verificado no número de artigos publicados em revistas científicas, artigos apresentados em congressos nacionais e internacionais, trabalhos publicados em formato de capítulo de livros e livros e eventos científicos sobre o tema, que utilizam os dados censitários do IBGE sobre os indígenas (BARBOSA et al., 2017; BASTOS et al., 2017; RAUPP et al., 2017; WONG, 2016; SANTOS et al., 2015; WONG; MORELL; CARVALHO, 2009; DIAS JUNIOR et al., 2007). Sem dúvida, a presença das informações sobre os indígenas nos bancos de dados censitários ampliou o acesso às informações sobre esse subgrupo populacional, proporcionado uma profusão de estudos a respeito.

Muitos pesquisadores e instituições governamentais e não governamentais tomam o ano 1991 como o marco da presença do indígena no questionário do Censo Demográfico brasileiro (IBGE, 2005; PAGLIARO; AZEVEDO; SANTOS, 2005). Esse entendimento por parte de diversos pesquisadores e instituições refere-se à presença explícita da categoria "indígena” no quesito cor/raça no questionário do Censo de 1991. Para eles, é somente a partir deste ano que os indígenas passaram a ser recenseados sem serem alocados em categorias que não a sua, como, por exemplo, a inclusão deste subgrupo na categoria "pardo". Sem dúvida, essa separação foi uma atitude acertada, pois, como ressalta Oliveira (1999, p. 199), "in order a have desirable conceptual strictness, the census color classification must consider the 'Indian' as a distinct category and not as one of the multiple possible manifestations of the 'pardo' category".

Mesmo reconhecendo todos os avanços implementados pelo IBGE nos Censos Demográficos a partir de 1991 referentes à população indígena, acreditamos que em três censos realizados anteriormente $(1872,1890,1960)$ é possível captar informações da população indígena de maneira direta, mesmo que nesses não tenha sido utilizada a mesma nomenclatura dos Censos de 1991 em diante.

É importante destacar que nos Censos de 1940 e 1950, mesmo não tendo o objetivo de detectar os indígenas, é possível localizar uma parcela da população brasileira falante de línguas indígenas, via quesito "língua falada no lar" (IBGE, 2008, 1950). Embora seja plausível pensar que esses falantes de línguas indígenas sejam indígenas, isso não pode ser afirmado categoricamente, pois não foram coletadas informações específicas sobre esse subgrupo populacional. Além disso, não existem os microdados destes Censos para uma possível tentativa de filtrar as informações utilizando dados como UF, município, urbano/ rural, cor/raça, por exemplo, para estimar a população indígena. Assim, acreditamos que os Censos de 1940 e 1950 não permitem captar os indígenas no Brasil, mas sim os falantes de línguas indígenas.

\section{Os indígenas nos Censos Demográficos brasileiros pré-1991}

Desde o império, o governo brasileiro vem fazendo o levantamento censitário no país. Foram realizados censos em 1872, 1890, 1900, 1920, coordenados pela Diretoria Geral de 
Estatística, e em 1940, 1950, 1960, ${ }^{1}$ 1970, 1980, 1991, 2000 e 2010, coordenados pelo IBGE (ANJOS, 2013; IBGE, 2008; OLIVEIRA; SIMÕES, 2005).

Como pode ser verificado no Quadro 1, nos Censos de 1872 e 1890, no quesito cor, a categoria "caboclo" representava a população indígena, como é relatado nas instruções do questionário utilizado na coleta dos dados (PAIVA et al., 2012; DIRECTORIA GERAL DE ESTATÍSTICA, 1922).

Nos Censos de 1900, 1920² e 1970, o quesito cor/raça não foi incluído (IBGE, 2005). No Censo de 1940, sob a designação de pardos, foram alocados os que registraram cor diferente de branco, preto e amarelo, ou foi lançado um traço no lugar da resposta (IBGE, 2005). Nos Censos de 1950 e 1980 foram utilizadas quatro categorias, agrupando todos os que registraram cor diferente de branco, preto e amarelo na categoria "pardo" (ANJOS, 2013). No Censo de 1960 foi incluída a categoria índia, para os indígenas residentes nas reservas, sendo que os indígenas residentes fora das reservas foram agrupados na categoria “pardo" (ANJOS, 2013). Nos Censos de 1991, 2000 e 2010 incluiu-se a categoria indígena, sendo que no questionário do Censo de 2010 também foram incorporadas questões sobre língua falada e etnia (IBGE, 2012). Nos Censos de 1980, 1991 e 2000 o quesito cor/raça foi pesquisado apenas na amostra e, em 2010, voltou a ser pesquisado no universo.

Dessa forma, antes de 1991, apenas nos Censos de 1872, 1890 e 1960 é possível levantar informações referentes à população indígena. Infelizmente, nos demais Censos em que foram coletadas informações sobre cor/raça, os indígenas foram alocados na categoria "pardo", juntamente com outros grupos de cor/raça que não branco, preto e amarelo, o que fez com que ficassem invisíveis nas estatísticas oficiais.

QUADRO 1

Classificação segundo cor/raça nos censos populacionais brasileiros

\begin{tabular}{|c|c|c|c|c|c|c|c|c|c|c|c|c|}
\hline Cor/raça & 1872 & 1890 & 1900 & 1920 & 1940 & 1950 & 1960 & 1970 & 1980 & 1991 & 2000 & 2010 \\
\hline Branca & $x$ & $x$ & & & $x$ & $x$ & $x$ & & $x$ & $x$ & $x$ & $x$ \\
\hline Preta & $x$ & $x$ & & & $x$ & $x$ & $x$ & & $x$ & $x$ & $x$ & $x$ \\
\hline Amarela & & & & & $x$ & $x$ & $x$ & & $x$ & $x$ & $x$ & $x$ \\
\hline Parda & $x$ & & & & $x$ & $x$ & $x$ & & $x$ & $x$ & $x$ & $x$ \\
\hline Indígena & & & & & & & & & & $x$ & $x$ & $x$ \\
\hline Índia & & & & & & & $x$ & & & & & \\
\hline Mestiça & & $x$ & & & & & & & & & & \\
\hline Caboclo & $x$ & $x$ & & & & & & & & & & \\
\hline
\end{tabular}

Fonte: Anjos (2013); IBGE (2005); Piza e Rosemberg (1998).

\footnotetext{
${ }^{1}$ A partir de 1960 o levantamento censitário passou a utilizar um questionário para amostra da população, além do questionário do universo.

2 O Censo de 1920 não traz o quesito cor/raça no questionário, mas o relatório referente ao recenseamento populacional, publicado em 1922, apresenta um tópico analítico que discute a evolução da raça no Brasil. É um documento histórico riquíssimo, que demonstra como o Estado brasileiro enxergava as raças que compunham o país. Além disso, o relatório apresenta algumas estatísticas sobre os povos indígenas e os negros (escravos ou não), captados pelos Censos de 1872 e 1890 (DIRECTORIA GERAL DE ESTATÍSTICA, 1922).
} 


\section{Os Censos de 1872 e 1890}

0 boletim de família utilizado no Censo de 1872 deixa claro que apenas os indígenas "puros" deveriam ser classificados na categoria "caboclo", sendo que qualquer outra definição para além de branco e preto deveria ser incluída na categoria "pardo" (PAIVA et al., 2012). Os resultados levantados por este Censo apontam para um contingente de 386.955 indígenas em 1872, representando 3,9\% da população total do Brasil (OLIVEIRA, 1999; DIRECTORIA GERAL DE ESTATÍSTICA, 1922).

No levantamento de 1890, novamente, a categoria "caboclo" foi utilizada para contar os indígenas. Os resultados indicam que $9,6 \%$ da população brasileira foi considerada indígena, totalizando 1,3 milhão de pessoas (OLIVEIRA, 1999; DIRECTORIA GERAL DE ESTATísTICA, 1922).

Não obstante, existem interpretações distintas sobre esses números. Para Oliveira (1999), tais dados não contariam apenas os indígenas, mas também os mestiços, o que explicaria o grande aumento populacional deste subgrupo no período entre 1872 e 1890. Por outro lado, a publicação da Directoria Geral de Estatística (1922, p. 343) entende que a categoria "caboclo" é a que representa os indígenas; inclusive os mestiços aparecem separados dos caboclos.

Até onde é de nosso conhecimento, não existem os microdados destes levantamentos populacionais, apenas os relatórios com os dados consolidados. Para o Censo de 1872 é possível obter informações sobre sexo, educação, religião, situação jurídica, situação conjugal, província, grandes regiões, profissão, defeitos físicos, dentre outras, segundo cor/ raça do indivíduo (DIRECTORIA GERAL DE ESTATÍSTICA, 1876). Tais informações permitem a construção do perfil dos indígenas no período do império, mesmo com os problemas identificados ${ }^{3}$ na coleta de dados do Censo de 1872 (PAIVA et al., 2012; PAIVA; MARTINS, 1983). Para o Censo de 1890, não conseguimos localizar as publicações com as informações sobre cor/raça da população, apenas segundo sexo, unidade da federação e localidade. Os dados sobre os indígenas encontrados referem-se apenas ao total contabilizado no recenseamento, que podem ser verificados, por exemplo, na publicação da Diretoria Geral de Estatística (1922).

\section{Censo de 1960}

Em relação ao Censo de 1960, além dos relatórios impressos pelo IBGE, ainda é possível acessá-lo por meio dos microdados arquivados no Integrated Public Uso

\footnotetext{
${ }^{3}$ No Censo de 1872, as informações não foram captadas simultaneamente em todo o território nacional e foi utilizada a autodeclaração censitária. Estes dois pontos podem afetar a qualidade dos dados porque o gap temporal pode influenciar no tamanho das populações e a autodeclaração pode ser influenciada pela "falta de uniformidade das respostas, omissão e de erros de interpretação das questões”, que são agravados pelo fato de o Brasil ter um enorme contingente de analfabetos (PAIVA et al., 2012, p.12).
} 
Microdata Series, da Universidade de Minnesota (IPUMS, 2018). ${ }^{4}$ Segundo o relatório do IPUMS, foram perdidos os dados dos estados de Rondônia, Acre, Amazonas, Roraima, Pará, Amapá, Maranhão, Piauí, Espírito Santo, Guanabara e Santa Catarina. Tal perda produz um impacto profundo nas análises sobre os povos indígenas, uma vez que as informações dos estados que historicamente apresentam os maiores contingentes das populações nativas não estão mais disponíveis ao nível dos microdados. De qualquer forma, é possível produzir informações dos indígenas residentes nos demais estados da federação via microdados.

No questionário do Censo de $1960,{ }^{5}$ o quesito cor/raça apresenta cinco categorias: branco, preto, amarelo, pardo e índia, sendo que os indígenas vivendo fora dos aldeamentos deveriam ser classificados como "pardos" e aqueles vivendo em aldeamentos ou postos indígenas deveriam ser classificados como "índios" (ANJOS, 2013).

Talvez um fato que deixe dúvidas aos pesquisadores em relação às possibilidades de acessar os dados da população indígena no Censo de 1960, pelo menos dos indígenas residentes em aldeamentos, possa ser atribuído às publicações do IBGE. No próprio relatório do instituto destaca-se que "A pesquisa relativa à cor foi circunscrita a quatro grupos: Brancos, Pretos, Amarelos e Pardos, incluindo-se neste último as declarações que diziam respeito aos índios" (IBGE, 1960, p. XIII). Ou seja, para efeitos de publicação, as informações sobre os indígenas aldeados, a término do campo, foram agrupadas na categoria "parda", que já incluía os indígenas urbanos. Acreditamos que a consulta apenas às publicações do IBGE, no que diz respeito ao Censo de 1960, pode induzir os pesquisadores a erros, no que se refere à captação das informações sobre os indígenas.

Assim sendo, é possível estudar os indígenas a partir dos microdados censitários de 1960, mesmo que apenas uma pequena parcela deles. Para ilustrar esta possibilidade, a Tabela 1 apresenta a distribuição percentual dos indígenas, segundo sexo, região geográfica, situação do domicílio e grupo etário no Brasil em 1960, a partir dos microdados.

Como já explicado, os dados da região Norte não estão mais disponíveis. A Tabela 1 mostra que, nas quatro regiões analisadas, havia uma proporção maior de homens indígenas do que mulheres (embora a diferença entre os sexos seja pequena), quase metade da população residia no Centro-Oeste e quase $97 \%$ estavam nas áreas rurais do país. Por fim, percebe-se que a população indígena era bastante jovem, já que mais de $65 \%$ possuíam até 29 anos.

\footnotetext{
${ }^{4}$ É importante destacar que o Censo de 1960 também está disponível no Centro de Estudos da Metrópole (CEM-USP, http://web.fflch.usp.br/centrodametropole/), mas o banco disponibilizado não contém os pesos, tanto da pessoa quanto do domicílio.

${ }^{5}$ Neste Censo, a coleta das informações sobre cor/raça levava em conta a autodeclaração do entrevistado (IBGE, 2008).
} 
TABELA 1

Distribuição dos indígenas, segundo, sexo, região geográfica, situação do domicílio e grupo etário Brasil - 1960

\begin{tabular}{lr}
\hline Variáveis & $\%$ \\
\hline Sexo & 50,9 \\
$\quad$ Homem & 49,1 \\
$\quad$ Mulher & 13,0 \\
Região & 5,4 \\
$\quad$ Nordeste & 33,5 \\
$\quad$ Sudeste & 48,2 \\
Sul & \\
$\quad$ Centro-Oeste & 3,4 \\
Situação do domicílio & 96,6 \\
$\quad$ Urbano & \\
$\quad$ Rural & 14,0 \\
Grupo etário & 16,1 \\
0-4 anos & 11,1 \\
5-9 anos & 9,4 \\
$10-14$ anos & 15,9 \\
$15-19$ anos & 11,5 \\
$20-29$ anos & 9,9 \\
$30-39$ anos & 5,2 \\
$40-49$ anos & 7,1 \\
$50-59$ anos & 10.460 \\
60 anos e mais &
\end{tabular}

Fonte: Censo Demográfico, 1960.

Nota: Dados gerados utilizando o peso da amostra.

Dados sem as informações da região Norte e dos estados de Santa Catarina, Espírito Santo, Guanabara, Maranhão e Piauí.

\section{Conclusão}

Nos levantamentos e análises produzidos para este breve trabalho, foram identificadas informações exclusivas dos indígenas em alguns censos realizados no período anterior a 1991, a saber, os Censos de 1872, 1890 e 1960.

No Censo de 1872 é possível realizar algumas caracterizações da população indígena no período imperial. Os relatórios que sobreviveram ao período permitem agrupar determinadas características da população segundo cor/raça.

Em relação ao Censo de 1890, não conseguimos localizar relatórios com o nível de detalhamento do que foi encontrado para o Censo de 1872. Assim, apenas o número absoluto da população indígena, para o total do Brasil, está disponível.

Já para o Censo de 1960 é possível acessar as informações sobre os indígenas a partir dos microdados, e não por meio das publicações oficiais do IBGE. Mesmo não tendo as informações completas, isto é, para todo o país e para os indígenas urbanos, podem ser delineadas, mesmo que minimamente, algumas características socioeconômicas e demográficas deste subgrupo populacional. 
Com a possibilidade de utilizar os microdados, acreditamos ser urgente um trabalho meticuloso com as informações que sobreviveram, para podermos conhecer mesmo que só uma pequena parcela dos povos indígenas aldeados no Brasil em 1960. Este resgate histórico pode ser bastante útil para entendermos os dados presentes. Sem dúvida um desafio para os demógrafos atuais.

Por fim, é importante destacar que existem diferenças nos aspectos metodológicos na captura das informações censitárias, bem como nos graus de cobertura, que podem inviabilizar a comparação dos resultados sobre a população indígena no Brasil antes e depois de 1991. Os conceitos utilizados são diferentes, como pode ser visto ao comparar o Censo de 1872 e o de 2010. 0 primeiro reforça a ideia de "índio puro" e o segundo abarca a autopercepção do indivíduo enquanto seu pertencimento ou não a um povo indígena, independentemente de saber ou não suas origens étnicas ou saber ou não falar uma língua indígena.

Mesmo sendo extremamente complicadas as comparações entre os dados pré-1991 com aqueles recentemente produzidos pelo IBGE, acreditamos ser possível produzir algumas características pontuais dos povos indígenas que habitavam o Brasil em um passado não muito distante.

\section{Referências}

ANJOS, G. dos. A questão "cor" ou "raça" nos censos nacionais. Indicadores Econômicos FEE, v. 41, n. 1, p. 103-118, 2013.

BASTOS, J. L.; SANTOS, R. V.; CRUZ, O. G.; LONGO, L. A. F. B.; SILVA, L. O. Características sociodemográficas de indígenas nos censos brasileiros de 2000 e 2010: uma abordagem comparativa. Cadernos de Saúde Pública, v. 33, supl. 1, p. e00085516, 2017.

CAMPOS, M. B.; ESTANISLAU, B. R. Demografia dos povos indígenas: os censos demográficos como ponto de vista. Revista Brasileira de Estudos de População, v. 33, n. 2, p. 441-449, 2016.

DIAS JÚNIOR, C. S.; VERONA, A. P. A.; PENA, J. L.; MACHADO-COELHO, G. L. L. Fecundidade das mulheres autodeclaradas indígenas residentes em Minas Gerais, Brasil: uma análise a partir do Censo Demográfico 2000. Cadernos de Saúde Pública, v. 24, n. 11, p. 2477-2486, 2008.

DIRECTORIA GERAL DE ESTATÍSTICA.Recenseamento do Brazil. Volume 1, Introdução. Rio de Janeiro: Typ. da Estatística, 1922.

Commercial, 1876.

Recenseamento geral do império de 1872. Rio de Janeiro: Typ. Leuzinger; Tip.

IBGE - Instituto Brasileiro de Geografia e Estatística. Características étnico-raciais da população. Um estudo das categorias de classificação de cor ou raça. Rio de Janeiro: IBGE, 2008. Disponível em: 〈https://biblioteca.ibge.gov.br/visualizacao/livros/liv49891.pdf〉. Acesso em: 8 jun. 2018.

Censo Demográfico 2010: características gerais dos indígenas. Resultados do universo. Rio de Janeiro: IBGE, 2012. Disponível em: 〈https://biblioteca.ibge.gov.br/visualizacao/ periodicos/95/cd_2010_indigenas_universo.pdf〉. Acesso em: 18 jun. 2018.

IBGE, 1960.

Censo Demográfico de 1960 - Alagoas e Sergipe. Volume 1, Tomo VII. Rio de Janeiro: 
Censo Demográfico de 1940 - População e Habitação. Volume 2. Rio de Janeiro: IBGE, 1950. Disponível em: 〈https://biblioteca.ibge.gov.br/visualizacao/periodicos/65/ cd_1940_v2_br.pdf〉. Acesso em: 03 set. 2018.

Tendências demográficas: uma análise dos indígenas com base nos resultados da amostra dos Censos Demográficos 1991 e 2000. Rio de Janeiro: IBGE, 2005. Disponível em: 〈https://biblioteca.ibge.gov.br/visualizacao/livros/liv28099.pdf〉. Acesso em: 8 jun. 2018.

MINNESOTA POPULATION CENTER. Integrated Public Use Microdata Series, International: version 7.0 [dataset]. Minneapolis, MN: IPUMS, 2018. Disponível em: 〈https://doi.org/10.18128/D020. V7.0> Acesso em: 8 jun. 2018.

OLIVEIRA, J. P. Entering and leaving the "melting pot": a history of Brazilian indians in the national censuses. Journal of Latin American Anthropology, v. 4, n. 2, p. 190-211, 1999.

OLIVEIRA, L. A. P.; SIMÕES, C. C. S. O IBGE e as pesquisas populacionais. Revista Brasileira de Estudos da População, São Paulo, v. 22, n. 2, p. 291-302, 2005.

PAGLIARO, H.; AZEVEDO, M. M.; SANTOS, R. V. Demografia dos povos indígenas no Brasil: um panorama crítico. In: PAGIARO, H.; AZEVEDO, M. M.; SANTOS, R. V. (Org.). Demografia dos povos indígenas no Brasil. Rio de Janeiro: Editora Fiocruz, 2005. p.11-32.

PAIVA, C. et al. (Org.). Publicação crítica do recenseamento geral do império do Brasil de 1872. Belo Horizonte: Núcleo de Pesquisa em História Econômica e Demográfica, Centro de Desenvolvimento e Planejamento Regional (Cedeplar), 2012. Disponível em: 〈http://www.nphed. cedeplar.ufmg.br/pop-72-brasil/>. Acesso em: 18 jun. 2018.

PAIVA, C. A.; MARTINS, R. B. Um estudo crítico do recenseamento de 1872. Relatório de Pesquisa. Belo Horizonte: PNPE, 1983. Mimeografado.

PEREIRA, N. O. M.; SANTOS, R. V.; AZEVEDO, M. M. Perfil demográfico e socioeconômico das pessoas que se autodeclararam 'indígenas' nos censos demográficos de 1991 e 2000. In: PAGIARO, H.; AZEVEDO, M. M.; SANTOS, R. V. (Org.). Demografia dos povos indígenas no Brasil. Rio de Janeiro: Editora Fiocruz, 2005. p.155-166.

RAUPP, L.; FÁVARO, T. R.; CUNHA, G. M.; SANTOS, R. V. Condições de saneamento e desigualdades de cor/raça no Brasil urbano: uma análise com foco na população indígena com base no Censo Demográfico de 2010. Revista Brasileira de Epidemiologia, v. 20, n. 1, p. 1-15, 2017.

SANTOS, R. V.; BASTOS, J. L.; CRUZ, O. G.; LONGO, L. A. F. B.; FLOWERS, N. M.; PEREIRA, N. O. $M$. Parity of indigenous and non-indigenous women in Brazil: does the reported number of children born depend upon who answers national census questions? Plos One, v. 10, n. 4, p. e0123826, 2015.

WONG, L. L. R. Tendências da fecundidade dos povos indígenas nos Censos Demográficos brasileiros de 1991 a 2010. Revista Brasileira de Estudos de População, v. 33, n. 2, p. 399-421, 2016.

WONG, L. L. R.; MORELL, M. G. G.; CARVALHO, R. L. Notas sobre o comportamento reprodutivo da população autodeclarada indígena: Censos Demográficos 1991 e 2000. Revista Brasileira de Estudos de População, v. 26, n. 1, p. 61-75, 2009.

\section{Sobre os autores}

Claudio Santiago Dias Júnior é doutor em Demografia pela Universidade Federal de Minas Gerais (UFMG). Professor do Departamento de Sociologia da UFMG. 
Ana Paula Verona é PhD em Demografia pela The University of Texas at Austin. Professora do Departamento de Demografia e pesquisadora do Centro de Desenvolvimento e Planejamento Regional (Cedeplar) da Universidade Federal de Minas Gerais (UFMG).

\section{Endereço para correspondência}

Claudio Santiago Dias Júnior

Universidade Federal de Minas Gerais, Faculdade de Filosofia e Ciências Humanas, Departamento de Sociologia Avenida Presidente Antônio Carlos, 6627, Pampulha

31270-901 - Belo Horizonte-MG, Brasil

Ana Paula Verona

Universidade Federal de Minas Gerais, Faculdade de Ciências Econômicas, Departamento de Demografia

Avenida Presidente Antônio Carlos, 6627, Pamulha

31270-901 Belo - Horizonte-MG, Brasil

Recebido para publicação em 06/07/2018

Aceito para publicação em 24/10/2018 